Preface

\section{Hot Topics VII}

\author{
Emmanuel J. Favaloro, PhD, FFSc (RCPA) ${ }^{1}$ \\ ${ }^{1}$ Department of Haematology, Institute of Clinical Pathology and \\ Medical Research (ICPMR), Westmead Hospital, Westmead, Australia
}

Semin Thromb Hemost 2015;41:355-358.

Welcome to the seventh issue compilation of Seminars in Thrombosis \& Hemostasis entitled "Hot Topics."1-6 The previous issues have been very popular with our readership, as identified in subsequent analyses. ${ }^{7-12}$ Although Seminars in Thrombosis $\mathcal{E}$ Hemostasis is primarily a theme-driven publication, the occasional opportunity arises to publish composite issues containing more wide-ranging chapters of current interest and controversy. Accordingly, I am very pleased to present the latest "Hot Topics" issue (Part VII), containing items derived from various contributors, to provide a very interesting potpourri of material to share with our readership.

The issue begins with three "historical" articles, in part, continuing the historical articles we recently published as part of our 40th Anniversary celebrations. ${ }^{13,14}$ The first of these articles, on the complex history of the discovery and characterization of congenital factor X (FX) deficiency, is by Girolami and colleagues. ${ }^{15}$ FX plays a pivotal role in blood coagulation, representing the point at which all coagulation systems converge. Once activated to FXa, it converts prothrombin (FII) into thrombin (FIla). The discovery and characterization of FX and its deficiency is due to the description in 1956-1957 of three patients and families with a peculiar defect later demonstrated to be almost identical. These patients of diverse nationality were an American (Mr. Stuart), a British (Miss Prower), and a Swiss with Italian background (infant Delia B); this helps explain the earlier terminology of FX as Stuart-Prower factor. Although "almost identical," immunological and molecular biology studies subsequently revealed that the FX protein level and the mutation were different in each case, despite leading to basically similar clotting defects. Mr Stuart had no FX protein in his plasma and a Val298Met (homozygote) mutation and Miss Prower instead had a normal level of FX protein and an Arg287Trp + Asp282Asn (compound heterozygote) mutation. The analogous status of the Swiss patient was unknown. Subsequent studies described a few major variants that showed peculiar activation patterns and associated studies have informed on the great heterogeneity and complexity of the FX defect. The story of the discovery and classification of FX deficiency has contributed considerably to the understanding of blood coagulation. Although FX deficiency represents a rare bleeding disorder, ${ }^{16}$ most patients have mild disease unless factor levels are very low. Of additional interest, this paved the way to investigation of FX as a target of anticoagulation. These days, many of the anticoagulant drugs target FXa activity, including heparins and the non-vitamin $\mathrm{K}$ oral anticoagulants, such as rivaroxaban and apixaban. ${ }^{17-20}$

The second historical article, also by Girolami and colleagues, ${ }^{21}$ is on FVII, which has had several names over its short history, including Prothrombin Conversion Accelerator (SPCA), Proconvertin, Stable Factor, Co-Thromboplastin, Prothrombin Accelerator and Autoprothrombin I. FVII deficiency is now recognized to be one of the more common rare bleeding disorders. ${ }^{22}$ Nevertheless, FVII deficiency is only one of two congenital coagulation disorders that was not discovered by the description of a new bleeding patient whose clotting pattern did not fit the blood coagulation knowledge of the time (the other being FXIII deficiency). The existence of this factor (FVII), an additional factor capable of accelerating the conversion of prothrombin into thrombin, was suspected before 1951, the date in which the first family with FVII deficiency was discovered. Several investigators from both sides of the Atlantic were involved in the discovery of FVII deficiency; thus, several different names were tentatively suggested to define the new entity. However, FVII was eventually proposed to define this protein. Several variants of FVIII were described over subsequent years with peculiar reactivity toward tissue thromboplastins of different origin, and molecular biology techniques demonstrated several gene, usually missense, mutations. Later studies dealt with the relationship of FVII with tissue factor (TF) and activated FVII (FVIIa). Subsequent development of FVII concentrates, both plasma derived and recombinant, has facilitated therapeutic management of FVII deficient patients. Indeed, recombinant FVIIa has now widened its clinical utility far more
Address for correspondence Emmanuel J. Favaloro, PhD, FFSc (RCPA), Department of Haematology, Institute of Clinical Pathology and Medical Research (ICPMR), Westmead Hospital, Westmead, Australia (e-mail: emmanuel. favaloro@health.nsw.gov.au).
Issue Theme Hot Topics VII; Guest Editor, Emmanuel J. Favaloro, PhD, FFSc (RCPA).
Copyright @ $\odot 2015$ by Thieme Medical Publishers, Inc., 333 Seventh Avenue, New York, NY 10001, USA. Tel: +1(212) 584-4662.
DOI http://dx.doi.org/ 10.1055/s-0035-1554725. ISSN 0094-6176. 
broadly than just treatment of FVII deficiency, and is used offlabel to control bleeding in an array of clinical settings, including trauma, surgery, liver failure, post-partum hemorrhage and oral anticoagulant over-treatment. ${ }^{23}$

The third historical piece, by Lippi et al, on diagnostics in venous thromboembolism (VTE), ${ }^{24}$ takes us on a journal from its origin and then leads us toward the future. VTE is a prevalent and life-threatening condition that requires an accurate and timely diagnosis. The current diagnostic approach to this condition, entailing an efficient integration of clinical judgment, diagnostic imaging, and laboratory testing, is the result of decades of scientific and medical research. This article presents the major historical breakthroughs that have occurred in diagnostic imaging of both deep vein thrombosis (DVT) and pulmonary embolism (PE), as well as the various biological markers that have emerged from the laboratory bench, but which have only marginally managed to migrate toward the bedside. Notable here is the test we call D-dimer. In total, however, despite decades of research, the current diagnostic armamentarium for the effective diagnosis of VTE remains suboptimal, and there remains some wiggle room for the development of more effective diagnostic tools, which may include thrombus-targeted molecular imaging, infraredthermal-imaging (IRTI), analysis of thrombin generation and proteomics.

This issue of the journal then briefly re-explores the nonvitamin $\mathrm{K}$ antagonist oral anticoagulants (NOACs), also alternatively called direct oral anticoagulants (DOACs), as well as a host of alternate names. ${ }^{19,25}$ First Tufano and colleagues ${ }^{26}$ explore the relationship between the use of oral anticoagulants and the risk of osteoporosis, and ask the question-are the new anticoagulants better than the old in this regard? Indeed, several drugs have been associated with an increased risk of osteoporosis when used chronically. Coumarins (warfarin, acenocoumarol, phenprocoumon and fluindione), oral anticoagulants widely used for the prevention and treatment of arterial and venous thromboembolic diseases, are vitamin $\mathrm{K}$ antagonists that interfere with $\gamma$-carboxyglutamate formation, and so consequently inhibit the carboxylation of Gla proteins that are synthesized in the bone. These effects on bone turnover added to dietary restrictions in patients on anticoagulation are possible mechanisms inducing osteoporosis in coumarin users. However, conflicting evidence is available concerning the risk of osteoporosis and bone fractures in patients on treatment with these drugs. Nevertheless, this risk is likely to be clinically relevant in long-term (more than 1 year) coumarin users. The NOACs, recently introduced in clinical practice, appear to exert reduced interference on bone metabolism, although only limited in vitro and animal data are currently available, and their long-term effects will only become apparent at a future time.

Next, Ho and colleagues ${ }^{27}$ discuss the use of NOACs in the older frail population from both a hematological and geriatric perspective, as well as propose an algorithm on how these agents may be used in this frail population. As well known to readers of Seminars in Thrombosis \& Hemostasis, and as recently explored in an entire issue on anticoagulation, ${ }^{28}$ NOACs have changed the paradigm of anticoagulation man- agement, improving patient convenience as well as possibly reducing the incidence of spontaneous intracranial hemorrhage. ${ }^{18,29-31}$ However, there remain concerns with these agents due to the general lack of monitoring capacity ${ }^{19,32-35}$ and availability of readily assessable specific antidotes. ${ }^{36}$ This is particularly pertinent for the older population, ${ }^{37}$ and especially the frail elderly, who have multiple comorbidities, higher risk of falls and increased bleeding risk. This group has not been specifically studied in the NOAC randomized clinical trials and hence extrapolation of these data into this population should be performed cautiously.

The remaining articles in this issue represent a potpourri of thrombosis and hemostasis related papers. First, Cuker and coworkers $^{38}$ pose the question-can immune thrombocytopenia be cured with medical therapy? Primary immune thrombocytopenia (ITP) in adults often assumes a chronic course that requires persistent monitoring and treatment. Medical therapy has traditionally been viewed as a means of temporarily raising the platelet count with little or no potential to induce long-term platelet responses off treatment. However, several recent studies have tested the hypothesis that intensive medical therapy administered early in the disease course may ameliorate or even cure ITP. The authors of this review propose a biological rationale for medical intervention that simultaneously targets the innate and adaptive immune responses administered early in the course of disease. They also critically examine data on long-term outcomes after single-agent and multi-agent medical therapy.

Next, Hua and Chen present a state of the art review on procoagulant platelets and the pathways leading to cell death. ${ }^{39}$ Platelets are critical mediators of thrombosis and hemostasis. In response to agonist, platelets aggregate to form a thrombus via ligand binding of the glycoprotein IIb/IIIa receptor. However, activated platelets are heterogeneous in nature and a subset of platelets stimulated by strong agonists support the assembly of the coagulation complexes. It is proposed that these "procoagulant" platelets have a unique role in hemostasis and thrombosis as the link between primary and secondary hemostasis, localizing the thrombin burst required for fibrin formation to micro-domains within the platelet thrombus. Loss of procoagulant potential leads to bleeding while an increase is linked with propensity to thrombosis. While many features of the procoagulant platelet are known, the exact nature of the procoagulant platelet remains controversial. The authors note that many of the morphological and biochemical features of procoagulant platelets are also features of the cyclophilin D necrosis pathway. In overview, this review focuses on the distinct roles of platelet subpopulations, the identity of the procoagulant platelet and the potential role of the cell death pathways in regulating platelet procoagulant response.

Niccolai and coworkers ${ }^{40}$ then cover the topic of microparticles, as bridging the gap between autoimmunity and thrombosis. Microparticles are irregularly shaped small vesicles of heterogeneous size released from the plasma membrane in a tightly controlled process, in response to various stimuli. Microparticles have been associated with 
proinflammatory effects as well as with autoimmune processes, being a source of autoantigenic nuclear material that can form immune complexes. In addition, recent reports have linked a large number of autoimmune disorders to an increased risk of thrombosis, and microparticles seem to promote the potential for thrombotic events. In total, a growing mass of evidence supports the idea that microparticles may contribute to the generation of an inflammation-induced hypercoagulability state, having a relevant role in the pathogenesis of the thrombotic phenomena associated to autoimmune disease such as systemic lupus erythematosus (SLE), antiphospholipid antibody syndrome (APS) and systemic vasculitis. In summary, the authors focus this review on the procoagulant properties of circulating microparticles and analyze their contribution to the pathogenesis of autoimmune diseases. The topic of microparticles was previously explored in this journal several years ago. ${ }^{41,42}$

Lupoli and colleagues then review various links between methylation reactions, the redox balance and atherothrombosis. ${ }^{43}$ The authors begin by highlighting that homocysteine (Hcy) is irreversibly degraded to hydrogen sulfide $\left(\mathrm{H}_{2} \mathrm{~S}\right)$, an endogenous gasotransmitter that causes in vivo platelet activation via upregulation of phospholipase $\mathrm{A}_{2}$ and downstream boost of the arachidonate cascade, and that this mechanism involves a transsulfuration pathway. Based on such knowledge, clinical and experimental models on the relationships between Hcy and folate pathways in vascular disease and information on the Hcy controversy have been re-analyzed in the present review. Most interventional trials focused on Hcy lowering by folate administration did not exclude patients routinely taking the arachidonate inhibitor aspirin, and this may have influenced the results of some of these trials. Nutritional intake of folate also affects several enzymatic reactions of the methionine-Hcy cycle and associated one-carbon metabolism and, thereby, both methylation reactions and redox balance. It is therefore conceivable that that the abnormally high Hcy levels seen in pathologic states reflects a poorly elucidated perturbation of such reactions and of such balance. While it is unknown whether there is an interplay among $\mathrm{H}_{2} \mathrm{~S}$, methylation reactions, and redox balance, measuring the sole reduction of blood Hcy that follows folate administration may well be an oversimplified approach to a complex biologic perturbation. The need to investigate this complex framework is therefore thoroughly discussed in the present article.

This issue of Seminars in Thrombosis $\mathcal{E}$ Hemostasis concludes with a paper from Peetermans and colleagues, on Staphylococcus (S.) aureus, a leading cause of skin and soft tissue infections, foreign body infections and infective endocarditis. ${ }^{44}$ In case of endovascular infection with $S$. aureus, higher rates of cardiac valve destruction, embolic complications, severe sepsis, and death also occur. The unique capacity of $S$. aureus to induce clotting has been known for over a century; however, its role in virulence has long been controversial. S. aureus secretes 2 coagulases, staphylocoagulase, and von Willebrand factor binding protein, which both activate prothrombin to generate fibrin. A better understanding of the molecular mechanisms and new strategies to target the coagulases has highlighted their importance in S. aureus virulence. Coagulase activity is essential for the formation of $S$. aureus-fibrin-platelet microaggregates and for the homing of $S$. aureus to the vascular wall under flow. Absence or inhibition of $S$. aureus coagulase activity has improved outcome in disease models of skin infection, sepsis, catheter infection and endocarditis. The authors, therefore, review how the manipulation of the host's hemostatic system contributes to the diseasecausing potential of $S$. aureus and discuss the $S$. aureus coagulases as promising targets for novel therapeutic strategies.

As always, I would like to thank all the authors to this issue of Seminars in Thrombosis $\mathcal{E}$ Hemostasis for their original and comprehensive contributions. I also hope that you, representing the readership of this journal, find this issue of substantial interest. This will of course be determined in time, as measured and established for previous issues of 'Hot Topic' compilations. $^{1-12}$

\section{References}

1 Favaloro EJ. Hot topics I: A potpourri of current issues and controversies in thrombosis and hemostasis. Semin Thromb Hemost 2007;33(8):723-726

2 Favaloro EJ. Hot topics II: an editorial collection of current issues and controversies in thrombosis and hemostasis. Semin Thromb Hemost 2008;34(1):3-6

3 Favaloro EJ. Hot topics III. Preface. Semin Thromb Hemost 2012; 38(1):1-4

4 Favaloro EJ. Hot Topics IV. Semin Thromb Hemost 2013;39(1):1-4

5 Favaloro EJ. Hot topics V. Semin Thromb Hemost 2014;40(1):5-10

6 Favaloro EJ. Hot topics VI. Preface. Semin Thromb Hemost 2014; 40(7):713-717

7 Favaloro EJ. Editorial. Winners of the Inaugural Eberhard F. Mammen Award for Most Popular Article. Semin Thromb Hemost 2009; 35:587-590

8 Favaloro EJ. Winners of the 2010 Eberhard F. Mammen award for most popular article during 2008-2009. Semin Thromb Hemost 2010;36(7):685-692

9 Favaloro EJ. 2011 Eberhard F. Mammen award announcements. Semin Thromb Hemost 2011;37(5):431-439

10 Favaloro EJ. 2012 Eberhard F. Mammen award announcements. Semin Thromb Hemost 2012;38(5):425-432

11 Favaloro EJ. 2013 Eberhard F. Mammen award announcements. Semin Thromb Hemost 2013;39(6):567-574

12 Favaloro EJ. 2014 Eberhard F. Mammen award announcements: Part I - most popular articles. Semin Thromb Hemost 2014;40(4): 407-412

13 Favaloro EJ. A short history of Thrombosis and Hemostasis: part I (40th year celebratory issue). Semin Thromb Hemost 2014;40(5): 521-525

14 Favaloro EJ. A short history of thrombosis and hemostasis: part II (40th year celebratory issue). Semin Thromb Hemost 2014;40(8): $826-830$

15 Girolami A, Cosi E, Sambado L, Girolami B, Randi ML. The complex history of the discovery and characterization of congenital factor $\mathrm{X}$ deficiency. Semin Thromb Hemost 2015;41(4):359-365

16 Menegatti M, Peyvandi F. Factor X deficiency. Semin Thromb Hemost 2009;35(4):407-415 
17 Cuker A. Unfractionated heparin for the treatment of venous thromboembolism: best practices and areas of uncertainty. Semin Thromb Hemost 2012;38(6):593-599

18 McMahon BJ, Kwaan HC. The new or non-vitamin K antagonist oral anticoagulants: what have we learned since their debut. Semin Thromb Hemost 2015;41(2):188-194

19 Lippi G, Favaloro EJ. Recent guidelines and recommendations for laboratory assessment of the direct oral anticoagulants (DOACs): is there consensus? Clin Chem Lab Med 2015;53(2):185-197

20 Prandoni P, Milan M, Barbar S, et al. Incidence of arterial embolism in patients on treatment with old and new anticoagulants for venous thromboembolism. Semin Thromb Hemost 2015;41(2):154-159

21 Girolami A, Cosi E, Santarossa C, Ferrari S, Randi ML. The story of serum prothrombin conversion accelerator, proconvertin, stable factor, cothromboplastin, prothrombin accelerator or autoprothrombin I, and their subsequent merging into factor VII. Semin Thromb Hemost 2015;41(4):366-373

22 Mariani G, Bernardi F. Factor VII Deficiency. Semin Thromb Hemost 2009;35(4):400-406

23 Franchini M, Crestani S, Frattini F, Sissa C, Bonfanti C. Hemostatic agents for bleeding: recombinant activated factor VII and beyond. Semin Thromb Hemost 2015;41(3):342-347

24 Lippi G, Danese E, Favaloro EJ, Montagnana M, Franchini M. Diagnostics in venous thromboembolism: from origin to future prospects. Semin Thromb Hemost 2015;41(4):374-381

25 Husted S, de Caterina R, Andreotti F, et al; ESC Working Group on Thrombosis Task Force on Anticoagulants in Heart Disease. Nonvitamin $\mathrm{K}$ antagonist oral anticoagulants (NOACs): No longer new or novel. Thromb Haemost 2014;111(5):781-782

26 Tufano A, Coppola A, Contaldi P, Franchini M, Minno GD. Oral anticoagulant drugs and the risk of osteoporosis: new anticoagulants better than old? Semin Thromb Hemost 2015;41(4):382-388

27 Ho P, La Brooy B, Hayes L, Lim WK. Direct oral anticoagulants in frail older adults: a geriatric perspective. Semin Thromb Hemost 2015;41(4):389-394

28 Favaloro EJ. Anticoagulant therapy: present and future. Semin Thromb Hemost 2015;41(2):109-112

29 Senoo K, Lip GYH. Comparative efficacy and safety of the non-vitamin $\mathrm{K}$ antagonist oral anticoagulants for patients with nonvalvular atrial fibrillation. Semin Thromb Hemost 2015;41(2):146-153

30 Riva N, Ageno W. Pros and cons of vitamin K antagonists and nonvitamin $\mathrm{K}$ antagonist oral anticoagulants. Semin Thromb Hemost 2015;41(2):178-187
31 Schulman S. Treatment of venous thromboembolism with new oral anticoagulants according to patient risk. Semin Thromb Hemost 2015;41(2):160-165

32 Favaloro EJ, Lippi G. Laboratory testing in the era of the direct or non-Vitamin K antagonist oral anticoagulants (NOACs): A practical guide to measuring their activity and avoiding diagnostic errors. Semin Thromb Hemost 2015;41(2):208-227

33 Harenberg J, Du S, Krämer S, Weiss C, Krämer R, Wehling $M$ Patients' serum and urine as easily accessible samples for the measurement of non-vitamin $\mathrm{K}$ antagonist oral anticoagulants. Semin Thromb Hemost 2015;41(2):228-236

34 Harenberg J, Du S, Krämer S, et al. Novel methods for assessing oral direct factor Xa and thrombin inhibitors: use of point-of-care testing and urine samples. Semin Thromb Hemost 2013;39(1): 66-71

35 Harenberg J, Kraemer S, Du S, et al. Determination of direct oral anticoagulants from human serum samples. Semin Thromb Hemost 2014;40(1):129-134

36 Cervellin G, Benatti M, Bonfanti L, Lippi G. Quality and safety issues of direct oral anticoagulants in the emergency department. Semin Thromb Hemost 2015;41(3):348-354

37 Ko D, Hylek EM. Anticoagulation in the older adult: optimizing benefit and reducing risk. Semin Thromb Hemost 2014;40(6): 688-694

38 Cuker A, Prak ETL, Cines DB. Can immune thrombocytopenia be cured with medical therapy? Semin Thromb Hemost 2015;41(4): 395-404

39 Hua VM, Chen VMY. Procoagulant platelets and the pathways leading to cell death. Semin Thromb Hemost 2015;41(4):405-412

40 Niccolai E, Emmi G, Squatrito D, et al. Microparticles: bridging the gap between autoimmunity and thrombosis. Semin Thromb Hemost 2015;41(4):413-422

41 Key NS, Kwaan HC. Microparticles in thrombosis and hemostasis. Semin Thromb Hemost 2010;36(8):805-806

42 Lacroix R, Dignat-George F. Microparticles: new protagonists in pericellular and intravascular proteolysis. Semin Thromb Hemost 2013;39(1):33-39

43 Lupoli R, Di Minno A, Spadarella G, et al. Methylation reactions, the redox balance and atherothrombosis: the search for a link with hydrogen sulphide. Semin Thromb Hemost 2015;41(4):423-432

44 Peetermans M, Verhamme P, Vanassche T. Coagulase activity by Staphylococcus aureus: a potential target for therapy? Semin Thromb Hemost 2015;41(4):433-444 